\title{
Elementos para uma crítica da leitura semiológica das representações na cerâmica grega antiga
}

José Antonio Dabdab Trabulsi

Universidade Federal de Ouro Preto

Image et céramique grecque. Actes du Colloque de Rouen, 25-26 novembre 1982. Publications de l'Université de Rouen, no 96, Rouen, 1983, édités par F. LISSARRAGUE et F. THELAMON.

TRABULSI, J. A. D. Elementos para uma crítica da leitura semiológica das representações na cerâmica grega antiga. Classicn, Belo Forizonte, 3:157-164, 1990.

RESUMẼ: A partir des Actes du Colloque de Rouen et d'autres publications récentes, je formule certaines critiques des méthodes sémiologiques de lecture des images antiques, notamment le "gel" des changements et mutations historiques.

Toda uma série de trabalhos recentes publicados na França desenvolvem uma leitura das imagens na cerâmica que se apresenta em ruptura com as interpretações tradicionais. Esses trabalhos, que eu examinarei brevemente aqui, propõem uma leitura "semiológica" dos vasos gregos. Esta corrente é, ainda hoje, uma entre muitas outras, mas a lembrança do passado recente me faz pensar que, uma vez mais, esta "última moda vinda de Paris" pode dominar o nosso "prêt-à-penser" brasileiro, ao ponto de se tornar a interpretação dominante e exclusiva desse tipo de documentos.

Este pequeno ensaio tem por objetivo não condenar em bloco estas pesquisas ou subestimar o seu alcance intelectual, mas, antes, examinar os seus limites metodológicos. Com este objetivo, apre- 
sentarei os princípios básicos dessas pesquisas e tentarei fazer a sua crítica; em seguida, examinarei alguns dos seus resultados num domínio que me é familiar, o das imagens dionisíacas.

Tomemos de início um ponto de referência firme e cômodo: no Colóquio de Rouen (França) de 1982, dedicado à cerâmica grega, os problemas teóricos e metodológicos estiveram no centro das discussões. A título de introdução, Pauline Schimitt-Pantel e Françoise Thélamon fizeram o repertório dos principais pontos do debate atual (Image et céramique: 9-20). Vou tentar resumir o pensamento destas duas especialistas:

1. Em muitos trabalhos, "a imagem funciona o mais das vezes como ilustração de um discurso histórico inteiramente construído a partir de outros documentos, seja para corroborar as fontes escritas, seja para fundamentar tal hipótese do historiador. No pior dos casos, ela tem uma função puramente de ilustração estética e pode inclusive ser suprimida, o que acontece por vezes" (Image et céramique: 9) ;

2. Ainda a respeito da construção do discurso histórico, elas dizem: "O mais das vezes o discurso do historiador é construído em primeiro lugar a partir das fontes escritas, às quais ele dá prioridade, como se só a elas fosse reconhecido o estatuto de documento" (Image et céramique: 10) ;

3. As autoras criticam com vigor a equação imagem $=$ tradição popular, em oposição aos textos, que apresentariam uma tradição mais nobre.

Antes de continuar, podemos dizer o seguinte: concordo perfeitamente em ver a imagem nos vasos de cerâmica como representações, como documentos no pleno sentido da palavra e até como "monumentos" à maneira de Foucault (cf. Durand In: Image et céramique: 170), com uma lógica própria, e, através disso, vejo o perigo que corremos se a olharmos sempre como figuração da realidade direta. Mas, isto dito, eu não acho, como as autoras, "que passamos sem dúvida ao largo das questões propriamente históricas" (Image et céramique: 10) se solicitarmos das imagens informações "au premier dégré". A semiologia das imagens, no 
que se refere aos vasos gregos (mas sem dúvida também de maneira geral) não será mais útil que a "abordagem tradicional" que ela condena, a não ser que ela incorpore e ultrapasse as conquistas desta última. Ela não pode negá-las (o que a semiologia faz por vezes) pela simples razão de que os móveis, roupas, armas, utensílios e outros elementos de "cultura material" que os pintores tinham sob os olhos e que eles representavam (ainda que eles os transformassem e deformassem, o que parece óbvio) eram precisamente gregos (e mais que isso, arcaicos ou helenísticos, atenienses ou cretenses, e por aí afora), e não chineses ou contemporâneos. A mesma observação se aplica, na minha opinião, aos aspectos menos concretos da representação.

Quando ao ponto $\mathrm{n}^{\circ} 3$, nenhum historiador da arte sério jamais pretendeu fazer deste corte uma explicação exclusiva e definitiva. Os estudos como o de Flacelière e Devambez sobre Héracles (Flacelière; Devambez 1966), que as autoras criticam, ou os de Metzger (Metzger 1951) só falam de nuances, pois as mediações entre texto e imagem, por um lado, e entre a grande pintura, a escultura e a pintura dos vasos, por outro lado, são muito complexas. Mas ninguém poderá negar que o pintor de vasos, pela destinação mais ampla (mais ou menos ampla segundo o tipo de vaso) dos seus trabalhos, estava mais próximo das tradições populares, ou, para falar de forma mais precisa, mais próximo das interpretações mais populares da ideologia religiosa nobre, do que, por exemplo, o poeta épico ou lírico.

Continuemos. P. Schimitt-Pantel e F. Thélamon distinguem uma outra modalidade de abordagem das imagens que consiste em constituir o corpus de imagens para um tema histórico. Elas criticam os que "fabricam assim, a partir das imagens, documentos para a história. Eles consideram com efeito que estes documentos iconográficos são fontes susceptíveis de completar, de enriquecer os temas escolhidos pelo historiador, de responder certas questões às quais a documentação essencialmente textual não permite responder. A questão parte da história, a resposta volta à história. Impõe-se à imagem questões vindas do exterior, ao invés de se permanecer atento aos problemas que a própria imagem levanta" (Image et céramique: 14). A proposta que resulta desta crítica impediria, 
consequientemente, que se tomasse, para a constituição de um corpus, através de uma escolha restrita num conjunto numeroso de documentos, as imagens de uma figura divina, por exemplo. A crítica das autoras é de que "este tipo de abordagem, que segue um corpus voluntariamente fechado, impede que se perceba todas as interferências entre imagens. O fio condutor foi escolhido antes mesmo de se olhar as cenas" (Image et céramique: 16).

Ora, qualquer que seja a perspectiva adotada, é preciso partir de alguma coisa. Mais ingênuo do que escolher um ponto de partida é acreditar que se possa fazer abstração de todo conhecimento (ou preconceito) prévio. Talvez seja útil lembrar, com as autoras (Image et céramique: 16), que as imagens dos vasos de cerâmica não são uma "fotografia" da realidade, da mesma forma que uma cena mitológica não é sempre a "ilustração" de um texto. Mas é preciso ser prudente e não erigir isso em contra-sistema pois, se é verdade que, por exemplo, muito poucos acontecimentos históricos precisos foram pintados, e quase nada sobre o funcionamento da cidade, é não menos verdade que, por exemplo, o sucesso retumbante das Bacantes de Eurípides exerceu uma grande influência sobre as imagens dionisíacas ulteriores, para citar apenas um caso que me é familiar (Dabdab Trabulsi 1990). Para dar um outro exemplo, nós podemos demonstrar que se vemos fontes, a multiplicação das cenas de colheita de uva ou das atividades relativas ao azeite na cerâmica ática do $\mathrm{IV}^{\circ}$ século, isso tem uma relação certa e direta com processos históricos precisos e identificáveis.

Esta advertência parece indispensável, pois alguns chegaram até a negar o valor de certos resultados bastante seguros da pesquisa na área, como os trabalhos de Boardman sobre Héracles, ou as conclusões relativas à datação da reforma hoplítica a partir da cerâmica, por Salmon, Cartledge e outros (Image et céramique: 15). As imagens não são, é claro, simplesmente um "reflexo" da realidade ou a "ilustração" de um relato; mas a tendência que pretende negar toda e qualquer interferência do político (e mesmo da política) é tão parcial quanto o seu contrário. Imaginemos o sorriso irônico que nos provocaria um historiador que afirmasse que os westerns ou as histórias do Super-homem não têm nada a ver com o imperialismo norte-americano; ou ainda um outro que pretendesse 
constituir um corpus homogêneo das imagens cinematográficas do Super-homem e do Rambo como se não tivesse ocorrido o psico-drama do Vietnam entre os dois!

Nós sabemos que as atitudes dos gregos em relação à imagem eram diferentes das nossas, sobretudo antes da lenta maturação da teoria platônica da mimesis; é claro que um longo caminho resta ainda pela frente para sabermos "quais eram os signos pelos quais um espectador grego compreendia imediatamente que tal cena era a representada" segundo a feliz formulação de J.-P. Vernant (Image et céramique: 179), como ele lia os vasos. Ele não o fazia certamente como um chinês, talvez não exatamente como nós. Em resumo: é preciso construir uma teoria da recepção ao mesmo tempo em que se faz a análise formal das imagens. Mas esta abordagem, penso eu, não exclui uma leitura "au premier dégré". Se nós renunciamos a trabalhar assim, não podemos mais fazer história grega, mas apenas "o retrato de uma civilização" ou, no melhor dos casos, uma boa antropologia estrutural, que utiliza a história como uma enciclopédia, "resfria" a história grega para fazer dela (quaisquer que sejam os retoques e nuances) um quadro inalterado do arcaísmo até o período romano.

Chegamos então aqui a um problema de fundo, o de saber em que medida uma semiologia da imagem é compatível com as necessidades do historiador, sobretudo quando a pesquisa incide sobre longos períodos e mecanismos de mudança. Pois, quanto a isto, há problemas enormes e que não se limitam ao estudo da imagem. O próprio R. Barthes desconfiava da duração: "Em princípio o corpus deve eliminar ao máximo os elementos diacrônicos, ele deve coincidir com um estado do sistema, com um corte da história" (Blarthes, Éléments de sémiologie). Isto me parece um reconhecimento honesto da insuficiência de todo estruturalismo para dar conta da diacronia - e C. Lévi-Strauss pôde atravessar uma vida de trabalho intelectual sem mudar nem um pouco sua atitude em relação à história. A busca da interdisciplinaridade é um belo projeto, mas por vezes ele só leva a falsas esperanças, pois nem todos os debates sobre o "imperialismo" de uma disciplina sobre as outras são simples "rixas de vizinhança"; alguns são o resultado de impasses teóricos muito concretos. Para não irmos muito 
longe daquilo que nos ocupa agora, basta ler Barthes: "o projeto semiológico ou o projeto estruturalista não negam de forma alguma a necessidade da análise sociológica. Eles só fazem estabelecer precisamente o seu lugar no conjunto da análise" (Barthes 1981 :40). Viva a semiologia, ciência geral da humanidade!

Há, portanto, sem dúvida, um problema de fundo, que é a busca do ponto (ou dos pontos) de articulação efetiva entre o estruturalismo (seja em antropologia ou em semiologia) e a história. Mas há também o problema, mais imediato, interior à semiologia, do estabelecimento de malhas de leitura adaptadas aos diferentes assuntos, pois me parece evidente que a malha eficaz construida para a leitura de imagens publicitárias não convém de forma alguma aos ex-votos ou aos vasos gregos. Esta é a condição indispensável para que a "démarche" semiológica possa se tornar enriquecedora para o historiador (cf. Cousin 1979:81-88). Enriquecedora é o termo que cabe neste caso, pois ele deixa claro que de forma nenhuma a semiologia substituirá o trabalho específico do historiador.

Quanto a esta "condição", o mínimo que se pode dizer é que a pesquisa só faz começar. Assim, nós nos surpreendemos ao ler um dos raros historiadores que se dedicou efetivamente ao assunto afirmar que "a idéia que eu guardo é que, apesar de tudo, da imagem nós podemos extorquir um certo número de confissões que podem ser mais ricas, pois involuntárias, do que as que obtemos de um discurso bem dominado e controlado" (Vovelle 1979: $71 \mathrm{sq}$ ). Depois da tortura do texto, vamos à tortura da imagem!. . Vovelle parece aqui em atraso em relação aos próprios semiólogos que, como Rio, já abandonaram esta solução de facilidade: "Vemos então que este segundo nivel vem infirmar radicalmente tudo o que parecia instituir a priori a transparência da imagem em oposição à opacidade da palavra" (Rio 1978).

Para terminar, vejamos o que a semiologia da imagem pode trazer de novo no domínio da imagem grega e mais precisamente dionisíaca. "Semiologia da imagem" é dizer muito, pois que se trata, de fato, sob a influência mais ou menos forte da semiologia, do encontro do estruturalismo da "Escola de Paris" com os estudos sobre a cerâmica grega. Com efeito, faz já alguns anos, e após muitas críticas que mostravam o pouco interesse do grupo que se 
formou em torno de J.-P. Vernant por tudo o que se referia à cultura material, que uma série de trabalhos foram desenvolvidos sobre a imagem grega. A respeito desses trabalhos, farei apenas algumas observações: são trabalhos inovadores que contribuíram muito para aprofundar a nossa compreensão do mundo antigo e sobretudo do universo mental dos antigos. Esses trabalhos, que contam com algumas obras-primas de análise estrutural, apresentam aos olhos do historiador limites importantes.

$\overline{\mathrm{E}}$ claro que o conhecimento do funcionamento, em sincronia, de uma sociedade, das mentalidades, etc., é indispensável ao historiador para que se saiba como, pelo jogo destes mecanismos e estruturas, o conjunto evolui. Assim, J.-P. Vernant estudou recentemente o problema da máscara numa série de trabalhos (Vernant $1985 \mathrm{a}$; Vernant $1985 \mathrm{~b}$; Vernant e Frontisi-Ducroux 1983) que insistem na "facilidade" como traço fundamental da figura divina de Dioniso, traço em torno do qual se articulam os conceitos de presença/ausência, de alteridade. Mas ele é levado, penso eu, a superestimar este aspecto pois, nas imagens gregas, a facilidade não é exclusividade das figuras que ele indica e, por outro lado, Dioniso é com muito maior frequiência representado de perfil que de frente (Dabdab Trabulsi 1990: capítulo 10).

Maria Daraki, por seu lado, num artigo (Daraki 1982) mais tarde integrado ao seu livro sobre Dioniso, analisa uma única imagem, a do famoso vaso de Exéquias, onde Dioniso navega (Munique, Antikensammlungen 2044). Partindo da imagem e com a ajuda da tradição literária, ela chega a mostrar que Dioniso desempenha aí um papel de "senhor das junções": "mais do que reunir em si duas autoridades justapostas, a do deus agrário por um lado, a de deus marinho por outro, Dioniso traça uma via de circulação que permite a passagem constante de um domínio ao outro". A análise de Daraki é bastante fina, mas, por um lado, eu não vejo porque esta percepção da imagem seria incompativel com outras como "a chegada do deus" ou "a procissão do navio" e, por outro lado, sua análise não é mais segura que outras. Os métodos semiológicos buscam com freqüência esconder sua parte de subjetividade (que é, penso eu, ainda maior que em muitos outros métodos) detrás do vocabulário técnico que forjaram. 
Quando Barthes fala de "bastité" ou da "italianité" em algumas imagens publicitárias, ele não é de forma alguma mais objetivo que os historiadores da arte grega que falam de "traços bárbaros" ou "elementos de êxtase" nas imagens dionisíacas. Para voltar à análise de Daraki, ela não é mais segura que outras na medida em que só faz intervir uma única imagem e, sobretudo, porque supõe que os gregos do $\mathrm{VI}^{\circ}$ século tinham a mesma percepcãa geométrica do espaço que nós (pois uma grande parte da demonstração repousa sobre a distribuição dos delfins e dos cachos de uva em torno do barco), o que ainda precisa ser demonstrado. Além disso, essa idéia de "circulação" em lugar da "justaposição" é problemática também: é muito provável que, num período de longa duração, uma personalidade divina seja o resultado de fusões que só adquirem mais tarde um aspecto coerente. $E$, freqüentemente, a diversidade dos epítetos divinos trai a multiplicidade das potências divinas que foram recuperadas pelo grande deus clássico.

Mais restrito e bem direcionado é o estudo de J.-L. Durand e F. Frontisi-Ducroux (Durand; Frontisi-Ducroux 1982) em que interpretam uma parte dos vasos com ídolos que mostram a máscara de Dioniso fixada num pilar, outrora agrupados por A. Frickenhaus (Frickenhaus 1912) e que suscitaram o famoso debate com M. Nilson e outros. Ainda que já se tenha demonstrado há mais de 30 anos (sobretudo E. Coche de la Ferté) que estas imagens do $V^{\vee}$ século não são a ilustração de uma festa precisa, elas aguardavam um estudo mais exaustivo. Os autores mostram que:

a articulação dos espaços que, nos stámnoi, faz com que se interpenetrem o lugar técnico do ritual do vinho e o lugar impreciso da dança, permite fazer passar a um deles as características do outro. Assim, pela utilização dos signos icônicos polivalentes que "escorregam" de uma face para a outra, o caráter hierático que marca a distribuição do vinho impõe um pouco sua aparência aos outros aspectos do culto evocados. O skyphos introduz na dança a gravidade da manipulação religiosa de que ele é objeto. A flauta que dá ritmo à procissão sacrificial ou à exaltação báquica faz eco àquela que toca para o deus. $\mathrm{E}$ o gesto de saudação vem se sobrepor à quebra do pulso que anuncia o início do transe. (Durand; Frontisi-Ducroux 1982 : 95). 
Temos aqui um estudo que leva em conta a história:

Sempre susceptível de explosão, de violência, sempre em vias de escapar - se se tenta reduzi-lo - em direção às formas perigosas da sedição e da selvageria, o dionisismo das mulheres em torno da máscada apresenta, numa série de imagens, sua face pacífica, compatível com os quadros da cidade que ele pode e poderia ainda outra vez ameaçar. (Durand; Frontisi-Ducroux 1982 : 108).

Todos estes estudos, que eu sem dúvida resumi com demasiada brevidade aqui, usam instrumentos conceituais tais como "práticas combinatórias", "constantes e distâncias", "percurso das imagens", "homogeneidade e homologia", "articulações lógicas", "valor de transição e de conjunção". O que me faz pensar numa verdadeira leitura geométrica dos vasos gregos. Com estes autores nós ficamos por vezes muito longe de noções como "signo", "significante e significado", "função semiótica", "relações sintagmáticas e paradigmáticas", "metáfora e metonímia", "linguagem e meta-linguagem" e muitas outras que fizeram a glória da semiologia.

Repito, ao concluir, que não tenho a menor intenção de diminuir o alcance desses trabalhos, mas desejo apenas examinar alguns limites de fundo dos métodos que, pela maneira como colocam os problemas, impedem que conclusões necessárias ao historiador possam ser atingidas. Eu só contesto uma coisa: a sua ambição imperialista. As leituras não-semiológicas dos vasos continuam, aos meus olhos, não apenas legítimas como muito necessárias, tais como as de Boardman e sua escola, para dar apenas um exemplo.

A Grécia antiga era muito bela, mas ela mudou. Desejar "entrar na cabeça dos antigos" para compreender melhor o seu mundo é um projeto belíssimo; "partir das imagens" é um bom método. Mas com a condição de sabermos também sair da cabeça dos atores da história, pois o trabalho de tantas gerações de historiadores nos fez conhecer muitas coisas sobre a Grécia que os gregos ignoravam. O trabalho do historiador não consiste apenas em nos restituir vários universos sociais e mentais sucessivos, mas também em reconhecer as forças e os mecanismos que os fizeram passar de uns a outros. O tempo, eis a nossa matéria-prima. 


\section{BIBLIOGRAFIA}

BARTHES, R. Eléments de sémiologie, Communications, IV.

BARTHES, R. Sémiologie et cinéma. In: Le grain de la voix. Paris, 1981.

COUSIN, B. Iconographie sérielle et histoire des mentalités. In: Iconographie et histoire des mentalités. Paris, 1979.

DABDAB TRABULSI, J. A. Dionysisme, pouvoir et société en Grèce jusqu'à la fin de l'époque classique. Paris, Belles Lettres, 1990.

DARAKI, M. Oinops pontos, la mer dionysiaque, Revue de lhistoire des religions, 199, $\mathrm{n}^{9} 1$ (1982): p. 3-22.

DURAND, J.-L.; FRONTISI-DUCROUX, F. Idoles, figures, image: autour de Dionysos, Revue archéologique (1982): p. 81-108.

F'LACELIERE, R.; DEVAMBEZ, P. Héraclès. Images et récits. Paris, 1966 .

FRICKENHAUS, A. Lenäenvasen. Berlin, 1912 .

METZGER, H. Les représentations dans la céramique attique du IV siècle. Paris, 1951 .

RlO, M. Signe et figure. Communications, XXIX (1978).

VERNANT, J.-P.; FRONTISI-DUCROUX, F. Figures du masque en Grèce ancienne. Journal de psychologie normale et pathologique, LXXX (1983): 53-69.

VERNANT, J.-P. La mort dans les yeux. Paris, 1985 (1985 a).

VERNANT, J.-P. Le Dionysos masqué des Bacchantes d'Euripide, L'Homme, XCIII (1985): 31-58. (1985 b)

VOVELLE, M. In: Iconographie et histoire des mentalités. Paris, 1979. 